\title{
What if stem cells turn into embryos in a dish?
}

Citation for published version (APA):

Pera, M. F., de Wert, G., Dondorp, W., Lovell-Badge, R., Mummery, C. L., Munsie, M., \& Tam, P. P. (2015). What if stem cells turn into embryos in a dish? Nature Methods, 12(10), 917-919. https://doi.org/10.1038/nmeth.3586

Document status and date:

Published: 01/10/2015

DOI:

$10.1038 /$ nmeth.3586

Document Version:

Publisher's PDF, also known as Version of record

Document license:

Taverne

Please check the document version of this publication:

- A submitted manuscript is the version of the article upon submission and before peer-review. There can be important differences between the submitted version and the official published version of record.

People interested in the research are advised to contact the author for the final version of the publication, or visit the DOI to the publisher's website.

- The final author version and the galley proof are versions of the publication after peer review.

- The final published version features the final layout of the paper including the volume, issue and page numbers.

Link to publication

\footnotetext{
General rights rights.

- You may freely distribute the URL identifying the publication in the public portal. please follow below link for the End User Agreement:

www.umlib.nl/taverne-license

Take down policy

If you believe that this document breaches copyright please contact us at:

repository@maastrichtuniversity.nl

providing details and we will investigate your claim.
}

Copyright and moral rights for the publications made accessible in the public portal are retained by the authors and/or other copyright owners and it is a condition of accessing publications that users recognise and abide by the legal requirements associated with these

- Users may download and print one copy of any publication from the public portal for the purpose of private study or research.

- You may not further distribute the material or use it for any profit-making activity or commercial gain

If the publication is distributed under the terms of Article $25 \mathrm{fa}$ of the Dutch Copyright Act, indicated by the "Taverne" license above, 


\title{
What if stem cells turn into embryos in a dish?
}

\author{
Martin F Pera ${ }^{1-3}$, Guido de Wert ${ }^{4}$, Wybo Dondorp ${ }^{4}$, Robin Lovell-Badge ${ }^{5}$, Christine L Mummery ${ }^{6}$, Megan Munsie ${ }^{1} \&$ \\ Patrick P Tam ${ }^{7,8}$
}

\begin{abstract}
Recent studies show that pluripotent stem cells can undergo self-organized development in vitro into structures that mimic the body plan of the post-implantation embryo. Modeling human embryogenesis in a dish opens up new possibilities for the study of early development and developmental disorders, but it may also raise substantial ethical concerns.
\end{abstract}

\begin{abstract}
A remarkable variety of body cell types can be developed from human pluripotent stem cells (PSCs) grown in vitro (Box 1). Studies over the past several years have shown that human PSCs grown in 3D can not only differentiate into specialized cells but also undergo self-assembly and morphogenesis to develop into a range of organoid structures, including brain, eye and gut ${ }^{1}$. Just in the past year, two reports ${ }^{2,3}$ have shown that under the right conditions, mouse and human PSCs in vitro can form structures that have some resemblance to embryos during gastrulation. This is a critical process that normally occurs several days after the embryo implants in the womb, and it is the means by which the body plan and various early tissue types, including the central nervous system, begin to develop. These fascinating findings offer potential uses for PSCs, but they may also raise important ethical and regulatory challenges.

PSCs can initiate the process of differentiation in vitro when they are
\end{abstract}

\footnotetext{
${ }^{1}$ Department of Anatomy and Neuroscience, University of Melbourne, Melbourne, Victoria, Australia.

${ }^{2}$ The Walter and Eliza Hall Institute for Medical Research, Parkville, Victoria, Australia. ${ }^{3}$ The Florey Neuroscience and Mental Health Institute, Parkville, Victoria, Australia. ${ }^{4}$ Department of Health, Ethics \& Society, Research Schools Care and Public Health Research Institute and GROW School for Oncology and Developmental Biology, Maastricht University, Maastricht, The Netherlands. ${ }^{5}$ Francis Crick Institute, Mill Hill, London, UK. ${ }^{6}$ Department of Anatomy and Embryology, Leiden University Medical Centre, Leiden, The Netherlands. ${ }^{7}$ Embryology Unit, Children's Medical Research Institute, Westmead, New South Wales, Australia. ${ }^{8}$ Discipline of Medicine, Sydney Medical School, University of Sydney, Sydney, New South Wales, Australia. ${ }^{8}$ These authors contributed equally to this work.

e-mail:mpera@unimelb.edu.au
}

deprived of factors required for the maintenance of pluripotency, or when they are cultured in floating aggregates that develop into structures known as embryoid bodies. If these cultures are then exposed to appropriate signaling molecules (morphogens) in the correct sequence and at concentrations known to direct specific cell-fate decisions during normal embryo development, they can differentiate to give desired cell types with timelines similar to those in the embryo. Although they mimic the processes that occur during embryonic development, differentiating cultures of PSCs do not generally form organized structures that resemble the embryo anatomically. However, in part by controlling the number of cells that are present in a group of PSCs when differentiation is initiated, the two recent studies mentioned above ${ }^{2,3}$ revealed that mouse and human PSCs are capable of giving rise to structures that recapitulate at least some aspects of the spatial organization of the embryo during and after gastrulation. This is a critical point in development, shortly after implantation (6.5 $\mathrm{d}$ and $14 \mathrm{~d}$ after fertilization in mouse and human, respectively), when the pluripotent cells of the embryo differentiate and reorganize to form the three germ layers that comprise the essential building blocks for further development of tissues and organs. The extent to which these structures (called gastruloids in the mouse studies) actually resemble the early postimplantation embryo will determine not only their usefulness as models for mammalian development, but also the level of public scrutiny that research on them will attract.

Nodal and Wnt are morphogens and key regulators of post-implantation embryonic development. Van den Brink et al. ${ }^{2}$ found that the exposure of mouse embryonic stem (ES) cells grown as aggregates of about 300 cells in suspension to either activin (which mimics Nodal) or activin combined with active Wnt signaling leads to the development of selforganized structures with some analogy to mouse embryos at embryonic day (E) 5.5-6.5 and $\mathrm{E}$ 7.5. In this system, differentiation is spatially regulated in a reproducible fashion in polarized structures. These contain cell lineages that are characteristic of the three classic embryonic germ layers: ectoderm, mesoderm and endoderm.

Using a different scheme, Warmflash et al. ${ }^{3}$ grew human ES cells in vitro in $2 \mathrm{D}$, but confined the colonies to circles of a few hundred micrometers in diameter by micropatterning their substrate. Human ES cell colonies typically show reproducible, self-organized patterning; cells express the highest levels of stem cell markers, such as those associated with pluripotency, on the outer edges of the colony, and these levels decline in a gradient toward the colony's center, where cells become primed for neural specification $^{4,5}$. However, Warmflash et al. ${ }^{3}$ showed that if spatially confined human ES cell colonies are exposed to the morphogen bone morphogenetic protein (BMP), cells expressing markers characteristic of each of the embryonic germ layers will be found in a reproducible, orderly arrangement of concentric rings, with ectoderm to the inside of the colony surrounded by a ring 


\section{BOX 1 DEFINITION OF TERMS}

Pluripotent stem cells: cultured cells that may be grown indefinitely in the laboratory and can turn into any type of body cell. This includes embryonic stem cells, induced pluripotent stem cells, and other types of cells, such as epiblast stem cells, that correspond to early stages of development.

Morphogenesis: the process that leads to formational changes in the developing embryo, such as the development of organs and the spatial relationship of the tissues.

Gastrulation: a stage of development in which the primary germ layers (ectoderm, mesoderm and definitive endoderm), from which all the fetal tissues will develop, are formed.

Germ layers: the ectoderm, mesoderm and definitive endoderm cell layers that form at gastrulation, from which all fetal and some extra-embryonic tissues develop.

Patterning: the acquisition of localized morphological or molecular characteristics by cell populations in a tissue or an organ.

Primitive streak: a structure that forms in the posterior region of the embryo and is the first visible sign of gastrulation. Epiblast cells ingress through the primitive streak and are allocated to the mesoderm or definitive endoderm.

Epithelial-to-mesenchyme transition: a process during which cells lose their epithelial characteristics and gain an irregular appearance, lose their tight connection to each other, disperse and may become migratory.

Extra-embryonic tissues: structures in the conceptus that arise from the zygote but do not contribute to the fetal tissues, including those derived from the trophoblast or from the primitive endoderm. These tissues support the growth of the embryo and are a source of signals for patterning.

Adapted from ref. 10

of mesoderm and then endoderm ${ }^{2}$. The authors also provide evidence that at the border between the outer edge of the colony and the inner sector, cells are undergoing the epithelial-to-mesenchymal transition characteristic of cells that are giving rise to the primitive streak, a structure typical of gastrulation and a key intermediate in germlayer formation.

The structures described by Warmflash et al. ${ }^{3}$ clearly do not equate to the human post-implantation embryo, in which the primitive streak first forms at the caudal midline of a flattened disk, not in a continuous ring around the structure. Importantly, the radially symmetrical system lacks the rostral-caudal patterning of the embryo in vivo. Moreover, the interpretation that the zones of the colony described correspond to embryonic germ layers is based on an examination of the expression of only a few genes, which yielded data that are consistent with, but not proof of, similarity with the embryonic germ layers in the embryo. In an important caveat, these markers are representative of germ layers in the mouse; there are no data from equivalent stages of human embryos.

It is likely that further work will lead to considerable refinement of the model. For example, in the mouse embryo, elaboration of the beginning of the body plan requires signals from extra-embryonic tissues that may not be adequately represented in the cultures described so far. However, the crucial factors that are produced by these extra-embryonic tissues could easily be supplied to help forge a better replica of the embryo. Alternatively, appropriate coculture with cells representative of extra-embryonic tissues formed from PSCs, or culture in combination with extra-embryonic membranes from animal embryos, could direct human cells toward more advanced organized development.

If it does become possible to create structures that more closely resemble the human post-implantation embryo, it will be important to consider both the scientific and the ethical and legal ramifications. Research on the human embryo is appropriately subject to stringent regulation in most jurisdictions. One commonly used set of standards was originally promulgated in the United Kingdom as a consequence of the Report of the Committee of Inquiry into Human Fertilisation and Embryology, which eventually led to the passing of the Human Fertilisation and Embryology Act in 1990. This is commonly known as the 14-day limit on embryo experimentation, which makes it illegal to keep an intact human embryo in vitro past 14 days of development or beyond the appearance of a primitive streak, whichever comes first. There were several reasons to choose these endpoints, but notably they represent the point of individuation, as the formation of the primitive streak is the last point at which twinning can occur. This stage also marks the beginnings of the central nervous system. An important point to consider, therefore, is whether the in vitro-derived structures reported by Warmflash et al. ${ }^{3}$ and by van den Brink et al. ${ }^{2}$ (if derived from human PSCs) could conceivably breach the 14-day rule. They clearly express some markers of the primitive streak and of cell types that are representative of the three germ layers formed during gastrulation, as well as markers of early central nervous systems, even if the structures obtained are not (yet) very embryo-like.

Images of human brain tissue or of an eye developing from PSCs in a dish certainly capture the imagination of the public, although in general they are positively received when considered alongside the scientific and clinical justifications for the experiments. However, the notion of growing a human embryo in a dish to a stage where the body plan is evident is liable to provoke considerable controversy, no matter whether the culture is derived directly from an embryo or from PSCs grown in conditions that enable self-organization.

Which types of tests can be applied to determine the degree to which these scientifically interesting structures actually model the human post-implantation embryo? Most of our knowledge of mammalian embryogenesis is based on studies done in the mouse, and although there is considerable evolutionary conservation of fundamental embryological mechanisms, the timing of development, the formation and arrangement of the extra-embryonic tissues and the overall morphology of the embryo itself are different in human and mouse. There is also evidence that master regulatory genes might have different roles in early development in the two species (for example, PAX6 (ref. 6) in early neural development and SOX17 (ref. 7) in germline development). Thus gene expression patterns described in the mouse embryo cannot be used definitively to identify putative embryonic structures in a human context. More information on gene 
expression in the post-implantation nonhuman primate embryo, and a comparison with embryo-like structures derived from PSCs from the same species, would be very useful in assigning identity to the discrete zones observed in the colonies.

Analysis of developmental potential provides a stronger and more direct approach. For example, the propagation of patterned colonies in culture systems that support post-implantation mammalian development could provide a dramatic demonstration of their ability to reach later embryonic stages, but this could prove problematic ethically. In the mouse, postimplantation embryo culture supports normal development up to E 10.5the equivalent of 4.5 weeks of human development and a stage at which the form of the embryo is clearly recognizable ${ }^{8}$. Of course, it is unknown whether it is feasible to maintain human embryos in culture for anywhere near this long.

The interpretation of the regulatory status of gastruloids and related structures derived from PSCs is also clouded from a legal perspective, because the definition of a human embryo varies across jurisdictions. Some countries do not define the embryo at all in legislation that deals with research into infertility treatment and related topics. Some specifically define an embryo as the product of the union of sperm and egg but leave open the possibility of reconsidering the definition, which many jurisdictions have done in light of advances in human somatic cell nuclear transfer. In a number of countries, including Germany, the regulations consider developmental potential in the definition of an embryo, which could capture a broad range of experimentally derived entities. The Dutch and Belgian Embryo Acts define the embryo as a cell or a collection of cells "with the capacity to develop into a human being." The Australian legislation defines the embryo as including "any other process that initiates organised development of a biological entity with a human nuclear genome or altered human nuclear genome that has the potential to develop up to, or beyond, the stage at which the primitive streak appears." In other words, current experimentation and future progress could lead to a situation in which potentially valuable experimentation is held back or compromised owing to a lack of clarity around the legal definition of the human embryo. For example, in Australia, stem cell-derived structures that mimic the primitive streak-stage embryo could fall under the definition of an embryo in current law. Or, considering the Dutch and Belgian legislation, one might need to determine whether gastruloids have the capacity for development into a human being-yet how could this be done, either scientifically or ethically?

Separately, if the experiments to create gastruloids are performed with induced PSCs, which have a genetic makeup identical to that of the original somatic cell donor, the work could be considered to equate to creating a cloned embryo, which would further complicate the regulatory picture. It should, however, be noted that in those countries that permit the generation of new human ES cell lines, it is generally considered acceptable to maintain cultures of embryonic cells beyond 14 days as long as the embryo is disaggregated or otherwise not maintained intact. Given that the gastruloids have developed from cell lines maintained in tissue culture, perhaps over many passages, it could be argued that they have no direct relationship with intact embryos and that the 14-day rule is thus irrelevant.

In view of the regulatory uncertainty, it might nevertheless be appropriate to ask whether any extant definition of a human embryo in law makes sense in biological terms and to scrutinize again the arguments for and against maintaining the 14-day limit. For example, it ought to be possible to specify the circumstances in which an extended time limit might be ethically and legally justified for the purposes of research.

Given scientific or clinical justification and appropriate ethical approval, there are many reasons for pursuing this research. In addition to providing fundamental knowledge about the early human embryo, the ability to study processes in post-implantation human development could provide important insight into developmental disorders. Failure of embryonic development in the first trimester is very common, but disorders that occur later in development or even postnatally might have their origins during events that take place around or shortly after gastrulation. Patterned PSC cultures have recently been used ${ }^{9}$ to assess the effects of teratogens. New technology for gene editing would enable medium- to high-throughput analysis of gene function during early human development. In addition, differentiation protocols for human PSCs that more closely approximate the processes in normal embryonic development could produce mature cell types with greater phenotypic fidelity to their counterparts in vivo than is possible with current techniques. This might improve disease models, drug screening and sources of cells for transplants.

The types of structures reported by van den Brink et al. ${ }^{2}$ and by Warmflash et al. ${ }^{3}$ are far from being embryos. We therefore do not think that they require immediate attention from regulators. However, it might be worth anticipating what could follow. For example, it may be possible to provide extra-embryonic tissues typical of the yolk sac and placenta, which could contribute to the patterning of the PSC-derived structures as well as help to nourish and support them. It may even be possible to combine human gastruloids with extra-embryonic cells from animals, so that the chimeric embryos thus created would be essentially human.

Paradoxically — and again, depending on the definition of the embryo used-such research could result, in the legal sense, in 'upgrading' gastruloids to real (human) embryos. Although most countries with relevant legislation conditionally allow research on surplus embryos created for fertility treatment, many categorically prohibit the creation of embryos specifically for research. This is permitted in the United Kingdom, with a license from the Human Fertilisation and Embryology Authority, but it is not permitted to make animal-human chimeras in which the majority of cells in the embryo proper are human.

Finally, we raise these issues because we think that widespread discussion of the science, its potential and its policy implications will help to shape a regulatory approach that enables ethical conduct of research that could lead to substantial health benefits. Moreover, the public must be engaged before it can be reassured that barriers will be respected.

\section{COMPETING FINANCIAL INTERESTS}

The authors declare no competing financial interests.

1. Lancaster, M.A. \& Knoblich, J.A. Science 345, 1247125 (2014).

2. van den Brink, S.C. et al. Development 141, 42314242 (2014).

3. Warmflash, A., Sorre, B., Etoc, F., Siggia, E.D. \& Brivanlou, A.H. Nat. Methods 11, 847-854 (2014).

4. Hough, S.R. et al. Stem Cell Rep. 2, 881-895 (2014)

5. Laslett, A.L. et al. BMC Dev. Biol. 7, 12 (2007).

6. Zhang, X. et al. Cell Stem Cell 7, 90-100 (2010).

7. Irie, N. et al. Cell 160, 253-268 (2015).

8. Rivera-Pérez, J.A., Jones, V. \& Tam, P.P. Methods Enzymol. 476, 185-203 (2010).

9. Xing, J., Toh, Y.C., Xu, S. \& Yu, H. Sci. Rep. 5, 10038 (2015).

10. Tam, P.P. \& Loebel, D.A. Nat. Rev. Genet. 8, 368-381 (2007). 